\title{
Differenz
}

Revista internacional de estudios heideggerianos y sus derivas contemporáneas

AÑO 2 NÚMERO 1: JULIO DE 2015. e-ISSN: 2386-4877 - DOI: 10.12795/Differenz.2015.i01.06

[pp.87-102]

Recibido: 31/05/2015

Aceptado: 20/06/2015

\section{Crítica a la interpretación heideggeriana de la sustancia aristotélica.}

\section{Criticism of the heideggerian interpretation of the aristotelian substance}

\author{
Carmen Segura Peraita \\ Universidad Complutense de Madrid
}

\section{Resumen:}

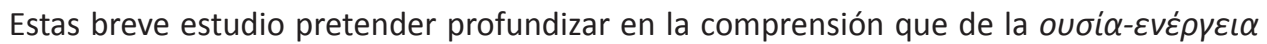
ofrece Heidegger en el capítulo VIII del Nietzsche. Una comprensión cuyo objeto no es otro que dar cuenta de la historia del ser. Aquella que lo habría entendido inicialmente como physis, pero enseguida como ovoí $\alpha$, actualitas y finalmente como Wirklichkeit. De lo que se trata es de valorar la pertinencia de los análisis heideggerianos y también de sus conclusiones. Al hacerlo, la cuestión específica que aquí se plantea es si en su trazado esquemático de esa historia del ser Heidegger procede con coherencia fenomenológicohermenéutica en su manera de realizar la investigación histórica.

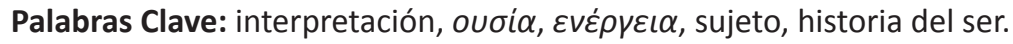




\section{Abstract:}

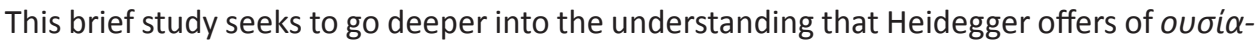
$\varepsilon v \varepsilon ́ \rho \gamma \varepsilon \iota \alpha$ in Chapter VIII of his Nietzsche. An understanding whose object is nothing other than accounting for the history of being. That which he had initially understood

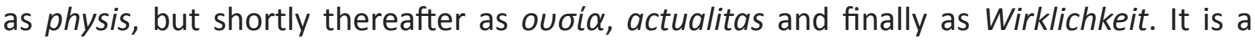
question of evaluating the pertinence of Heidegger's analyses and of his conclusions. In so doing, the specific issue that is considered here is whether in his schematic sketch of this Seinsgeschichte Heidegger proceeds with phenomenological-hermeneutic coherence in his manner of carrying out this historical investigation..

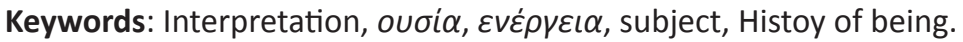

\section{Introducción}

Con independencia de la simpatía o animadversión que la lectura heideggeriana de Aristóteles despierte entre los especialistas -no sólo entre lo filósofos sino también entre los filólogos clásicos- de lo que no cabe duda es de que el pensador de Friburgo se destaca actualmente como uno de los más relevantes intérpretes del estagirita. En particular, porque no sólo ha revitalizado la filosofía aristotélica, sino porque lo ha hecho mediante una durísima crítica, al menos por lo que respecta a la central categoría aristotélica de sustancia, que es la que ahora nos ocupa. Tal crítica, como es bien sabido, ha socavado los fundamentos de la metafísica clásica, forzando a la filosofía actual a intentar una comprensión no sustancialista de lo que es.

A mi parecer, como ya he señalado en otras ocasiones, todavía está pendiente la tarea de estudiar, de manera sistemática y global, el conjunto de las interpretaciones hedieggerianas de Aristóteles. Sin duda ya se ha dado pasos muy importantes en esta dirección, pero está todavía pendiente una considerable tarea. Mi investigación actual está centrada prioritaria, aunque no absolutamente, en este campo de trabajo. Con ella pretendo contribuir modestamente a un propósito que, filosóficamente, no me parece relegable ${ }^{1}$.

A mi juicio, como ya he apuntado al comienzo, la crítica heidegeriana a la noción de sustancia constituye un aspecto fundamental, si no el más fundamental, de toda su

1 Entre otras puedo mencionar las siguientes investigaciones: "Heidegger: el Ereignis desde la reapropiación de la respuesta aristotélica al problema del movimiento", Daimon (aceptado para su publicación) y "Heidegger en torno a Aristóteles: una mirada fenomenológico-hermenéutica", Contrastes (aceptado para su publicación, 2015). 
interpretación del fundador de la metafísica occidental. Fue en efecto dicha crítica la que le permitió al discípulo de Husserl tachar de presencialista a toda la tradición metafísica occidental. Pues bien, al abordar la mencionada interpretación crítica que Heidegger

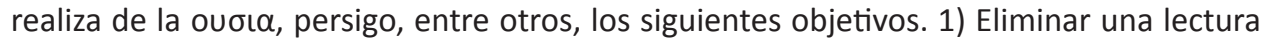
tópica de la crítica heideggeriana, que en ocasiones es el resultado de un insuficiente conocimiento de las filosofía de Aristóteles y también de la de Heidegger. 2) Aclarar algunos malentendidos, que en ocasiones provienen de ámbitos muy conservadores por lo que a la interpretación de los textos clásicos se refieren, poco proclive a admitir ningún mérito al heterodoxo intérprete del estagirita. 3) En consonancia con lo anterior, situar la interpretación heideggeriana de la aristotélica ovoı en el adecuado horizonte de comprensión; 4) analizar los rendimientos filosóficos que el debate establecido por Heidegger con Aristóteles tiene para su propio proyecto. Huelga decir que nada de esto significa que suscriba acríticamente las tesis heideggerianas; por el contrario, como se podrá advertir en este mismo trabajo, mi propósito es el de realizar una contribución realmente crítica, en el sentido más radical y positivo de esta palabra.

Con relación a los dos primeros objetivos, entiendo que es preciso realizar un examen riguroso tanto de la doctrina aristotélica de la sustancia como de la exégesis y crítica heideggeriana de la misma. En mi trabajo (del que aquí no caben sino unas pinceladas) lo llevo a cabo y, a mi juicio, el resultado de tal investigación es diferente del que habitualmente se acostumbra a verter. Formulado brevemente, se trata de lo que expondré en seguida,

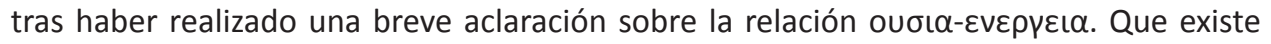
una estrechísima relación entre ambas nociones centrales resulta evidente. Pero también lo es que Heidegger no lee siempre del mismo modo esta vinculación. Pues bien, es cierto que no en todo momento Heidegger realizar una crítica ajustada de la ovoı $\alpha$ aristotélica, porque no en todo momento parece realizar una adecuada interpretación de la misma. Así, especialmente en los años 20'. Sin embargo, en los aspectos nucleares, su análisis es

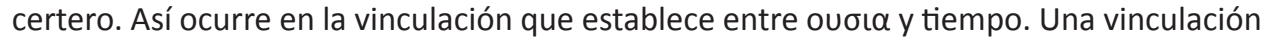
a la que nunca se había atendido tan explícita ni fructíferamente. Por otra parte, hay que recordar que el Heidegger de los años treinta, en su comentario a los primeros libros de la Física, realiza excelente interpretación de la $\varepsilon v \varepsilon \rho ү \varepsilon\llcorner\alpha$ en la que destaca su carácter de operación. Que el de Friburgo, entendiera la $\varepsilon v \varepsilon \rho y \varepsilon ı$ como operación es algo que muchos le niegan, aunque esta cuestión resulta bastante controvertida, puesto que en los numerosos textos posteriores a 1930 encontramos interpretaciones tanto en una dirección

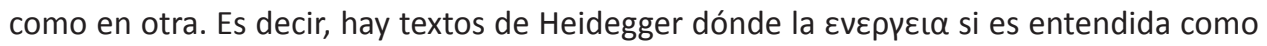


operación, pero también hay otros texto donde esa dimensión esencial de la $\varepsilon v \varepsilon \rho ү \varepsilon ı \alpha$ es ignorada e incluso, a menos de facto, puesta en cuestión².

Con relación a los dos últimos objetivos es necesario realizar las precisiones que siguen. Heidegger no se entendió nunca como un comentador ni como un intérprete ortodoxo de Aristóteles. Pero desde 1922, cuando en el Natorp Bericht dio forma al proyecto de destrucción, supo que en el origen de las categorías que conformaron la metafísica clásica se encontraba la comprensión aristotélica del movimiento, articulada categorialmente

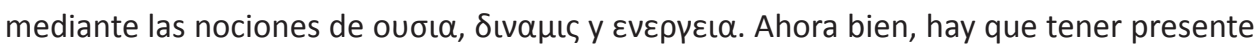
en todo momento que la lectura que Heidegger realiza de Aristóteles es fenomenológicohermenéutica, lo que significa tanto como decir que el discípulo de Husserl fuerza al de Platón a hablar su propio idioma o, mejor dicho, hace rendir los logros "metafísicos" para la causa fenomenológica, entendida more heideggeriano. La de Heidegger es una "ontología fenomenológica" en el sentido de que no se pregunta por el ente sino por la verdad del ser, por su sentido. Un sentido que es posible gracias a la copertenencia del Dasein y el ser. El Ereignis, esto es lo que en definitiva vertebra la búsqueda de un pensador que no hacer sino girar entorno a la vieja e insondable sentencia parmenídea que declara la identidad de pensar y ser. Es aquí donde hay que buscar los rendimientos de la sostenida discusión que Heidegger mantuvo con Aristóteles. Así, en "La tesis de Kant sobre el ser" dice el intérprete de Aristóteles: "Ser y pensar: en ese ' $y$ ' se esconde todo lo que debe ser pensado ya sea por toda la anterior filosofía o por el pensamiento de hoy"3. Éste es el horizonte dentro del que se mueve la confrontación de Heidegger con Aristóteles y sólo haciéndonos cargo de él, apropiándonoslo, estaremos en condiciones de analizar y valorar adecuadamente su interpretación.

De momento, sin embargo, la pretensión de la aportación que sigue es bastante más modesta. De lo que se trata en estas breves páginas es tan sólo de ahondar en la singular

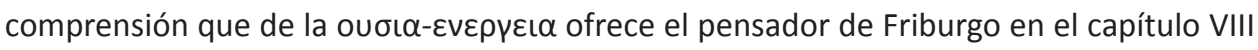
del Nietzsche. Una comprensión cuyo objeto no es otro que dar cuenta de la historia del ser. Aquella que lo entiende en su origen como physis, pero que deriva enseguida hacia la

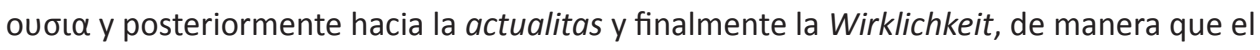
ser pasa a ser entendido como mera posición del pensar. Pues bien, la cuestión específica que aquí se plantea es si en su trazado esquemático de esa historia del ser Heidegger

2 Del magnífico conocimiento que de Aristóteles tenía Heidegger da cuenta especialmente, a mi parecer, el texto dedicado al análisis de la Física aristotélica de 1939 (HEIDEGGER, 1976), así como lo recogido en la segunda parte de Die Grundprobleme der Phänomenologie relativo a la consideración del tiempo en Aristóteles y a su tratamiento de la metabolé (HEIDEGGER, 1975).

3 HEIDEGGER, "La tesis de Kant sobre el ser,, p. 477 (386). 
procede con coherencia fenomenológico-hermenéutica en su manera de realizar la investigación histórica.

Pues bien para toda la interpretación que voy a exponer y criticar, Heidegger se basa en dos tesis (o hipótesis) nucleares, que se interrelacionan mutuamente y mutuamente se explican. La primera es que, desde sus orígenes, la metafísica entendió el ser como realidad efectiva (Wirklichkeit). La segunda es que, a la largo de la historia de la misma

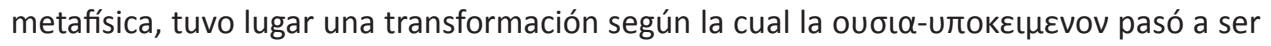
entendida como sujeto apofántico; dicha transformación habría llegado a su cenit con Kant.

En efecto, en el Nietzsche, Heidegger sostiene que ya desde sus mismos orígenes en Aristóteles el ser, en el sentido de la Existenz, fue entendido como realidad efectiva, Wirklichkeit. Esta afirmación toma como punto de apoyo, por una parte, la diferencia establecida por el Estagirita entre el qué-es (la esencia) y el que-es (la existencia). Por otra

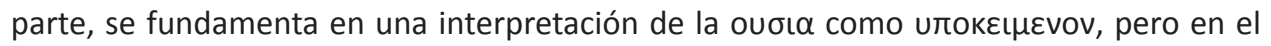
sentido de sujeto ontológico. Poner el acento en esta identificación le resulta imprescindible a Heidegger puesto que su crítica definitiva a la idea de ser como Wirklicheit, ya en Kant, se sostiene sobre la segunda tesis mencionada y que recuerdo a continuación.

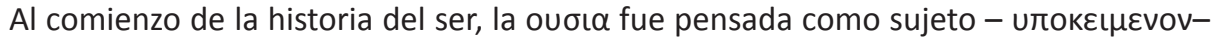
de todas sus determinaciones; es decir, como sujeto ontológico. Este sujeto era, siempre según Heidegger, lo que yaciendo desde sí delante estaba así presente y, por lo tanto era acto, actual. Ahora bien, en la Edad Media, debido ante todo al pensamiento creacionista, tal actualidad pasó a ser entendida como actualitas, en el sentido del mero estar puesto, del ser extra causas. Se advierte enseguida que, de la comprensión de la existencia como actualitas a la de ésta como Wirklichkeit, hay un corto trecho que recorrer.

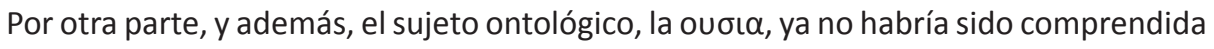
en la Edad Media, como lo que surge y permanece en la presencia (en el recuerdo de la physis) sino, de manera patente, como sujeto; de hecho, es traducida por substantia: lo que yace y permanece debajo, lo sub-puesto. Pero, dado que poco después la verdad como adaequatio pasó a ser concebida -merced a Descartes- como certeza, eso sujeto

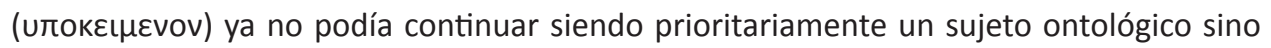
uno lógico. De este modo es, por tanto, como se inició la transformación del sujeto

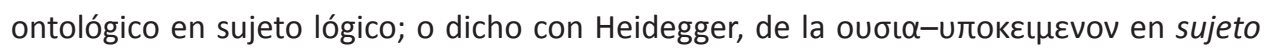
apofántico. 
A juicio de nuestro pensador, tal transformación sólo llegó a su plenitud en Kant, puesto que el yo pienso, que ya no es sustancia, se habría transformado plenamente en logos apofántico: en sujeto de sus todas sus determinaciones ${ }^{4}$.

A mi parecer, la lectura de Aristóteles, realizada por Heidegger en el Nietzsche (aunque no sólo), está hecha desde su peculiar y siempre vigente perspectiva kantiana y así también desde la influencia que sobre su comprensión de la Wirklicheit tuvo Suarez ${ }^{5}$. Sin embargo, esta última es una cuestión en la que no me puedo detener aquí, puesto que lo que me propongo realizar con esta aportación es lo que ya está contenido en el título de la

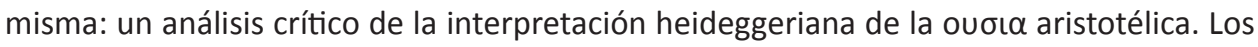
pasos que siguen se encaminan en esa dirección.

\section{La determinación metafísica del ser como "Wirklichkeit" y la transformación del sujeto ontológico en sujeto lógico}

Como ya he anunciado, para abordar el asunto de esta contribución comenzaré por atenerme a lo dicho por Heidegger en un breve texto de su Nietzsche. El que lleva por título, "La metafísica como historia del ser». Considero que la elección es atinada en la medida en que en estas páginas se encuentran decantadas las ideas que paulatinamente Heidegger fue elaborando a lo largo de un ya dilatado camino.

\subsection{El ser como Wirklichkeit}

Al comienzo de las páginas citadas, Heidegger formula una de sus tesis centrales; la primera de las dos que he enunciado. Que en metafísica, como "ente" vale lo real efectivo (das Wirkliche) ${ }^{6}$. Como ya he dicho, se trata de una comprensión que el pensador de Friburgo defiende desde el principio y que mantiene como hilo conductor de su análisis crítico hasta el final.

De hecho, sostiene arriesgadamente que esta distinción ya es operativa en Aristóteles. Así es, a su parecer la distinción entre el qué-es y el que-es constituye el comienzo de la metafísica, ya en Aristóteles, y permite la diferencia entre essentia, entendida como

4 Cf. mi artículo, "Heidegger: la copertenencia entre Dasein y ser. Una confrontación con Kant", Pensamiento, vol. 67, no 252, mayo-agosto, 2011, pp. 295-320.

5 A este respecto cf. mi libro Heidegger y la metafísica. Análisis críticos, Madrid, 2007, pp.193-202. 6 HEIDEGGER, 1961, 327. 
posibilidad, y existentia, comprendida como realidad efectiva. A juicio de Heidegger esta distinción es obvia para toda la metafísica, aunque en realidad, no lo sea en absoluto.

En la medida, sin embargo, en que Aristóteles piensa en primer lugar la ou $\sigma \iota \alpha$ (presencia) como $\varepsilon v \varepsilon \rho ү \varepsilon\llcorner\alpha$, y esta presencia no mienta otra cosa que lo que posteriormente, en una interpretación transformada, se llamará actualitas, realidad efectiva y existencia (Existenz, Dasein), la exposición aristotélica de la distinción muestra una preeminencia de lo que posteriormente se denomina existentia respecto de la essentia (...). Para Aristóteles el ser

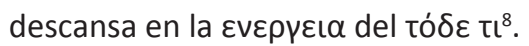

Estas palabras no dejan de ser sorprendentes, por varios motivos, de los que doy somera cuenta.

En primer lugar, he de hacer notar que en otros pasajes del mismo texto, Heidegger parece mantener una opinión diferente. Así es, en el epígrafe titulado «La transformación

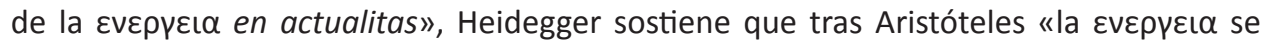
convierte en actualitas y ésta en realidad efectiva ${ }^{9}$. En estos momentos, Heidegger es de la opinión según la cual en la Edad Media -aunque las traducciones parecieran mantener el significado original- en realidad lo modificaron.

El pensador alemán da la impresión de vacilar en sus valoraciones. Por una parte, en el texto citado antes, dice que en la $\varepsilon v \varepsilon \rho y \varepsilon ı \alpha$ ya está el gérmen de la actualitas y la

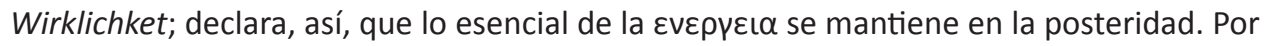
otra parte, poco después, sostiene que hay una sustantiva transformación de sentido en la actualitas que ya no expresa lo contenido en la $\varepsilon v \varepsilon \rho \gamma \varepsilon\llcorner\alpha$. A mi parecer esta aparente vacilación no es tal. Heidegger entiende la metafísica como destino acontecido, de manera que lo que comparece en el final había de estar desde el principio. De hecho mantiene, y con esto su postura parece quedar definitivamente clara, que a pesar del abismo que media entre la $\varepsilon v \varepsilon \rho \gamma \varepsilon\llcorner\alpha$ y la actualitas, la transformación del ser como esse actu está también preparada desde la esencia metafísica inicial del ser ${ }^{10}$.

En esta transformación la idea de Dios Creador juega, a su parecer, un papel fundamental. Desde el cristianismo, la $\alpha \rho \chi \eta$ se transforma en aıtı $\alpha$ y ésta, en definitiva, es Dios creador. Esto hace que la ex-sistencia se refiera al mero estar fuera de la causación. Así pues, Heidegger puede concluir lo que la tradición medieval rezaba: «la existentia es

7 lb., 329.

$8 \mathrm{lb} ., 334$.

$9 \mathrm{lb}$.

$10 \mathrm{lb} ., 339$. 
el actus, quo res sistitur, ponitur extra statum possibilitatis. Este actus es causalitas» ${ }^{11}$. En definitiva, ahora lo real existente es lo que es en acto, la actualitas, pero eso es, a su vez (o al menos puede ser comprendido así) das Wirkliche.

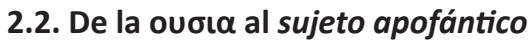

En la introducción de este estudio he afirmado que la segunda tesis fuerte en que se apoya la interpretación y crítica heideggerianas de la "comprensión tradicional" del ser, es la siguiente. Que a lo largo de la historia de la metafísica hubo una transformación por la cual la ouoı $\alpha$ griega pasó a ser entendida como sujeto apofántico.

En el mismo texto del Nietzsche que estoy analizando, Heidegger se esfuerza por mostrar que tal transformación tuvo lugar tal como él la entendió. Para hacerlo procede del siguiente modo. En primer lugar, aborda la comprensión aristotélica de la ouøı $\alpha$, de la que extrae las consecuencias pertinentes. Después dedica un apartado a mostrar que fue Descartes quien realizó la transformación de aquella en sujeto lógico; es decir, apofántico. Al hacerlo, insiste en varias ocasiones en que tal transformación sólo llegó a su plenitud con Kant.

A mi parecer, la interpretación heideggeriana -por lo que tiene que ver con la mencionada transformación- resulta sugerente y no está totalmente exenta de sentido. Considero, sin embargo y como ya he dicho, que su exégesis de Aristóteles, sobre la que hará pivotar los desarrollos posteriores, no se encuentra libre de algunas dificultades. Paso ya a exponer los pasos principales que da el pensador de Friburgo para afianzar su propia tesis respecto de la ouøı y sus transformación.

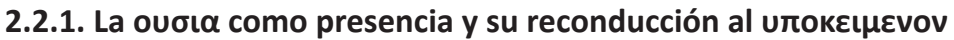

Pues bien, es conocida la tesis heideggeriana (que se remonta a Einführung in die Metaphysik) según la cual en el comienzo de la historia del ser, éste fue entendido como surgimiento - $\phi \cup \sigma \iota \varsigma-y$, en consecuencia, como $\alpha \lambda \eta \theta \varepsilon \alpha^{12}$. Ahora bien, esta concepción acabaría derivando en el demorarse: en un mantenerse presente y consistente en el ser, que así llega a ser entendido como ouøıa. Aquí comenzaría la historia propiamente dicha

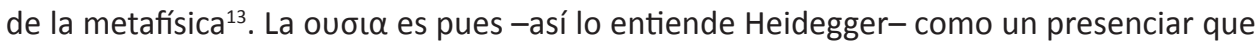

\section{$11 \mathrm{lb} ., 342$.}

12 "La physis es el ser mismo, merced al cual lo ente se hace y permanece visible por vez primera. Einführung in die Metaphysik, GA 40, pp. 16-17.

13 Cf. Nietzsche, p. 330. 


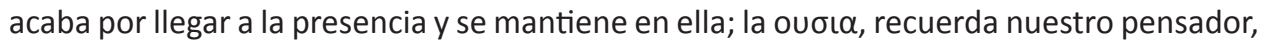

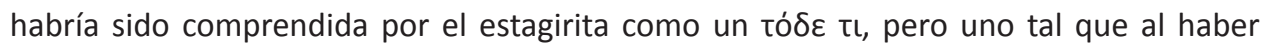

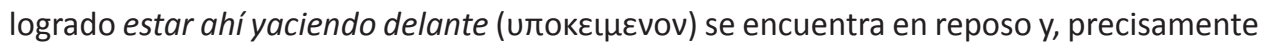
en ese reposo, es presencia, presente.

De esta inicial caracterización de la ouøı $\alpha$ por parte de Heidegger, hay que destacar, a mi parecer, dos aspectos.

a) Por una parte, con su descripción de la ouoı como un llegar a la presencia y mantenerse en ella, el pensador de Friburgo está reiterando su conocida acusación de presencialismo a la metafísica (una acusación que se remonta a 1924, cuando en el curso titulado Sophistes, la formula de manera explícita por vez primera).

b) Por otra parte, apoyándose en su caracterización de la ovoı $\alpha$ como un mero yacer

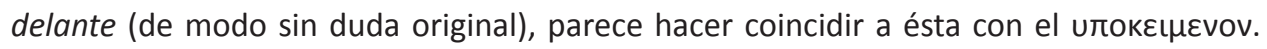

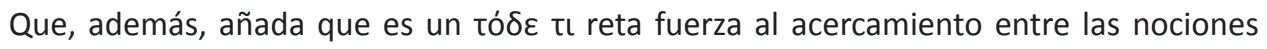
de entidad y sujeto. No parece caber duda, la intención del pensador friburgués es subrayar el carácter que de sujeto (nadie lo discute) tiene la ouoı $\alpha$. Aunque, a mi juicio, el modo en que lo hace desdibuja los perfiles nítidos y precisos con los que el estagirita la definió, también es cierto que hay elementos en la metafísica y en la lógica aristotélica (como veremos en seguida) que le permiten a Heidegger realizar la lectura buscada. No es mi propósito realizar un estudio filológico-crítico con relación a la interpretación que Heidegger hace de Aristóteles. No obstante, me resulta inesquivable la necesidad de apuntar, siquiera, ciertas precisiones.

En el libro VII de la Metafísica, Aristóteles afirma que lo que primariamente es, es la entidad individual: la ouoı $\alpha$.

La expresión "algo que es" se dice en muchos sentidos (...). De una parte, significa el qué-es y algo determinado y, de otra parte, la calidad, la cantidad o cualquiera otra de las cosas que se predican de este modo. Pues bien, si "lo que es" se dice tal en todos estos sentidos, es evidente que lo que es primero de ellos, es el qué referido a la entidad (...). Lo que primariamente es, lo que no es en ningún aspecto, sino simplemente, será la entidad $^{14}$.

Ésta es entendida como principio. Es decir, no como una mera suma de notas o predicados sino, si se me permite la expresión, como una orden-eso es también forma y así la denomina Aristóteles: forma específica, $\varepsilon\llcorner\delta \circ \varsigma-$, que desde sí misma se autoconstituye 
y autogestiona. Aunque, en cualquier caso, lo que hay es el individuo constituido desde la forma y por ella, también por el resto de sus determinaciones categoriales.

En el mismo libro, Aristóteles se pregunta a qué se debe llamar entidad, si a la esencia,

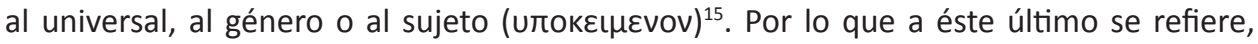
su respuesta es que, puesto que el sujeto es aquello de lo que se predica el resto de

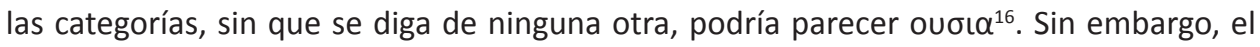

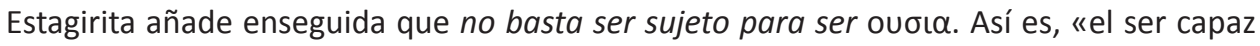
de existencia separada y el ser algo determinado parecen pertenecer en grado sumo a la entidad ${ }^{17}$. Por tanto, sólo será sustancia el sujeto que, además, reúna estos requisitos (por eso, la materia, $\cup \lambda \eta$, no lo es). En definitiva, como es sabido, la respuesta de Aristóteles es

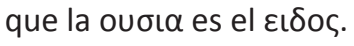

En el capítulo cuarto del libro VII de la Metafísica dice Aristóteles que «la esencia de cada cosa es lo que de cada cosa se dice que es por sí misma» ${ }^{18}$. Es decir, la esencia y la forma específica son lo mismo, pero contempladas desde dos puntos de vista diferentes: cuando contemplo desde fuera lo que algo es y lo defino, la definición recoge la esencia, la

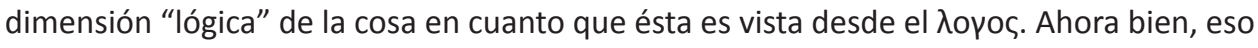
mismo, visto desde la naturaleza, en cuanto que principio constitutivo de un individuo,

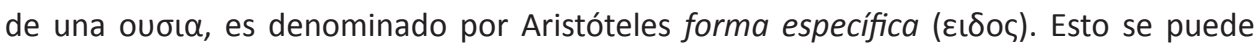
explicar también diciendo que la forma específica es la esencia "según la фuбıc", y que la

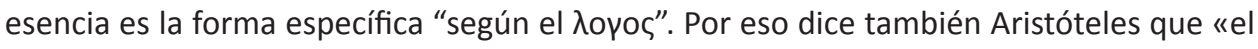
enunciado de la esencia de cada cosa es aquel enunciado que expresa la cosa misma sin que ella misma esté incluida en él ${ }^{19}$.

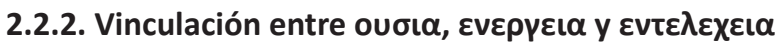

En las líneas siguientes del capítulo del Nietzsche al que me estoy refiriendo ${ }^{20}$, Heidegger va a tratar de la vinculación que existe en el pensamiento de Aristóteles entre ovola, $\varepsilon v \varepsilon \rho ү \varepsilon\llcorner\alpha$ y $\varepsilon \vee \tau \varepsilon \lambda \varepsilon \chi \varepsilon\llcorner\alpha$. Para lograrlo, tiene que realizar la tarea previa de mostrar la relación esencial que existe en la filosofía aristotélica entre movimiento y reposo. Después tendrá el camino expedito para que se advierta la conexión que se acaba de mencionar:

15 lb., 1028b 33-36.

16 lb., 37-38-1029a 31.

$17 \mathrm{lb} ., 1029$ a 28-30.

$18 \mathrm{lb} ., 1029 \mathrm{~b} 13$.

$19 l b ., 20$.

20 lb., pp. 331-332. 
«El reposo se muestra como un carácter de la presencia. Pero el reposo es un modo eminente de la movilidad. En la quietud el movimiento ha llegado a su acabamiento ${ }^{21}$.

Como se aprecia en el fragmento que acabo de citar, movimiento y reposo serían caracteres fundamentales del ser que se no se pueden considerar por separado en la medida en que el movimiento se encamina al reposo y éste es el fin de aquél. En opinión de Heidegger, estos caracteres están vinculados de manera esencial con el presenciar, puesto que ese presenciar es uno de los modos de la movilidad y el reposo.

Siempre a juicio de Heidegger, lo movido es llevado al estado y situación del presenciar;

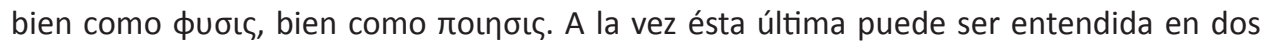
sentidos: como producir y como representar (de esta última interpretación que, sin duda, puede resultar insólita, se irá dando cuenta a lo largo de la exposición que sigue).

Recordando el ejemplo de la construcción de una casa (proporcionado por el mismo Aristóteles) se advierten dos cosas. La primera es que algo está en movimiento, está siendo producido. La segunda es que el reposo, tras el movimiento de la producción de la obra (apyov), preserva el acabamiento. La casa, dice Heidegger, reposa en su acabamiento y así se muestra en lo desoculto de su apariencia. Está a la vista, exhibida, expuesta, y nos muestra su aspecto (Aussehen: $\varepsilon(\delta \circ \varsigma)$. El apyov, la obra, es así lo que está expuesto en lo desoculto de su aspecto y se demora ahí; es, por tanto, uno de los modos del presenciar

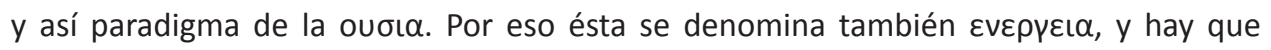
entender por $\varepsilon v \varepsilon \rho \gamma \varepsilon\llcorner\alpha$ lo que se ha realizado, lo efectuado y actual. De nuevo, lo real efectivo, das Wirkliche.

Como se puede advertir enseguida, sorprende que para realizar su explicación sobre la $\varepsilon v \varepsilon \rho \gamma \varepsilon\llcorner\alpha$, Heidegger recurra exclusivamente el ejemplo de una actividad poiética, puesto

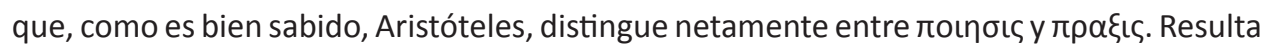
extraño además, que este pensador no recurra aquí para su explicación al capítulo 6 del libro IX de la Metafísica, que conocía bien²2.

En cualquier caso, siguiendo a Aristóteles, hay que decir que el acto no consiste en el mero estar detenido de lo ya acabado (lo que supondría entender el acto desde la k?

21 lb., p. 330.

22 En el libro IX de la Metafísica, Aristóteles continúa su tratamiento de la o[б]国; más aún, es ahí dónde finaliza su estudio acerca de ella. La nota diferencial, pero a la vez imprescindible, es que en él va a abordar la o[?] $\alpha$ desde la esencial estructura de potencia y acto. A este respecto, conviene señalar que, si resulta evidente la vinculación de estas "meta-categorías" con el movimiento, Aristóteles aclara que «la potencia y el acto van más allá de sus significados vinculados exclusivamente con el movimiento». Ib., 1, 1046 a 1. 
y la roınoıs, que es lo que parece ocurrir en el caso de la interpretación de Heidegger) sino que es un acto intensivo; esto es, actividad.

Por otra parte, aunque hayamos visto que Aristóteles distingue entre acto y potencia, también hemos de recordar su afirmación según la cual el movimiento es acto. Para empezar, como en tantas ocasiones, Aristóteles toma en consideración las opiniones: "La palabra "acto", vinculada a la realización plena, se ha extendido también a otras cosas, fundamentalmente a partir de los movimientos. En efecto, parece que el acto es, fundamentalmente, el movimiento ${ }^{23}$. De hecho, en el libro III de la Física, donde Aristóteles trata de la kıvnбıs, dice que: «es evidente que el movimiento es la actualidad de lo potencial en tanto que potencial» ${ }^{24}$. Además: «El movimiento es, pues, la actualidad de lo potencial, cuando al estar actualizándose opera no en cuanto a lo que es en sí mismo, sino en tanto que es movible ${ }^{25}$. Y también: "puesto que distinguimos en cada género lo actual y lo potencial, el movimiento es la actualidad de lo potencial en cuanto a tal ${ }^{26}$. Así pues, la kıvnoıs es una cierta actualidad, aunque no tenga la perfección de la insistencia en la acción sin perseguir un fin todavía no alcanzado (característica de la $\pi \rho \alpha \xi \iota \varsigma$ perfecta). Se trata de una actualidad activa, dinámica, vinculada al proceso de actualización, del estar cambiando algo (por ejemplo, construyéndose). Es el tipo de actualidad propia de lo potencial, pero sólo en tanto que sigue siendo potencial, porque una vez que deja de serlo y es acto, el movimiento (kıvnбıৎ) cesa.

Ahora bien, aunque el acto ( $\varepsilon v \varepsilon \rho \gamma \varepsilon\llcorner\alpha)$ se haya vinculado con el movimiento (y Aristóteles mantenga al menos en un sentido tal relación), el estagirita, establece (y de nuevo nos encontramos en la Metafísica IX, 6) una distinción que va a conducir a la que podríamos considerar su definición metafísica, en sentido estricto y no lato de "acto". Para lograr su objeto Aristóteles distingue entre distintos tipos de acciones (utilizando ahora la palabra en sentido amplio): por un lado, están las "acciones" que tienen término ( $\pi \varepsilon \rho \alpha \varsigma)$, y en las que el movimiento cesa una vez alcanzado ese fin (adelgazar, por ejemplo); entre éstas se incluye, en sentido lato, también la roınoıc. Como estas "acciones" no tienen el fin en sí mismas, no se les puede denominar propiamente acciones (al menos, no "acciones perfectas"). Para referirse a ellas Aristóteles propone hablar de "movimiento"

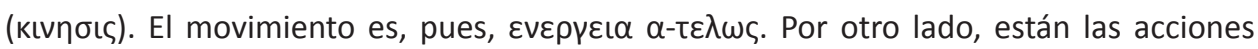
perfectas ( $\pi \rho \alpha \xi \iota \varsigma \alpha \kappa ı v \eta \sigma \iota \varsigma)$ ), aquéllas que tienen el fin en sí mismas, en las que se dan a la vez el fin y la acción. En éstas la plenitud no consiste en alcanzar un fin que está fuera

$23 \mathrm{lb} ., 3,1047 \mathrm{a} 30-32$.

24 Fisica, $201 \mathrm{~b} 5$.

$25 \mathrm{lb} ., 28$.

$26 \mathrm{lb}$, 201a 10. 
-como en el caso de la kıvnoıৎ- sino que la plenitud se da en la misma acción. Pues bien, es para estas acciones perfectas para las que Aristóteles propone reservar el uso de la

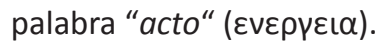

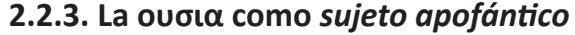

En el libro de las Categorías, la ouøı es caracterizada como sujeto, y sujeto eminente, aunque este sujeto desde luego no es la $u \lambda \eta$.

«Entidad, la así llamada con más propiedad, más primariamente y en más alto grado, es aquella que, ni se dice de un sujeto, ni está en un sujeto, v.g.: el hombre individual o el caballo individual ${ }^{27}$.

La entidad o primera categoría ni se dice de un sujeto ni está en un sujeto porque ella es sujeto, tanto de predicación como de inhesión. Así pues, no hay duda: la entidad es tanto sujeto lógico como ontológico. Pero esto significa en Aristóteles, ante todo, que de no existir las entidades primarias, no podría existir nada más. Esto es lo que le sirve a Heidegger para afirmar, con verdad, que la ouøı $\alpha$ aristotélica es, también, sujeto apofántico.

En el texto del Nietzsche que está acaparando nuestra atención, Heidegger dedica unas intensas páginas a estudiar lo relativo a la diferencia entre entidad primera y segunda. Para ello, como no puede ser de otro modo, se basa en los textos de Aristóteles. Después de haber analizado lo relativo a la entidad primera, pasa a estudiar lo que se refiere a las segundas. De ellas dice el estagirita: «se llaman entidades secundarias las especies a las que pertenecen las entidades primariamente así llamadas, tanto esas especies como sus géneros» ${ }^{28}$.

Sólo los predicados esenciales, los que contienen la esencia de un individuo, la definición de lo que algo es, constituyen entidades secundarias. Pero éstas no son un

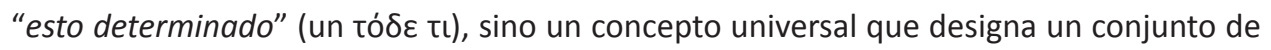
individuos ${ }^{29}$.

\section{Categorías 5, 2a 11-13.}

$28 \mathrm{lb}$., 2a 13-19. Por ejemplo, un ser humano no puede ser más o menos ser humano, ni con respecto a sí mismo ni en comparación con otros seres humanos.

29 «Verosímilmente, después de las entidades primarias, sólo las especies y los géneros, de entre las demás cosas, se llaman entidades secundarias; pues sólo ellas entre los predicados muestran la entidad primaria», Ib., 2b 30-32. 
Me parece necesario subrayar que hay una diferencia que, al parecer, pasó bastante desapercibida a los pensadores renacentistas y modernos (que también a Heidegger le interesa destacar); la que existe entre un individuo particular, que es un tó $\delta \varepsilon \tau \mathrm{\tau}$, y una esencia, que expresa lo que Aristóteles nos ha mostrado (ya se trate de una especie o un género). Al parecer, estos pensadores centraron toda su atención en las esencias, que llegaron a identificar con la posibilidad o lo posible. Ésta es la razón que explica que la existencia fuera entendida precisamente en esos siglos como realidad efectiva, Wiklichkeit: lo que es ahora (si no es siempre). Y esto en el sentido de que la existencia de un individuo es entendida como una "efectuación de la esencia" que para nada le afecta y que, por tanto es irrelevante.

Aunque tan sólo sea muy brevemente, en este orden de consideraciones, entiendo que se ha de recordar que hay una notable diferencia entre la potencia aristotélica y la posibilidad moderna. Según el estagirita, la potencia ( $\delta \iota v \alpha \mu \varsigma)$ pertenece al orden ontológico. Con ella, Aristóteles se refiere a algo que es -aunque en el modo de que puede llegar a ser, que no se ha realizado todavía de manera acabada-; por ese motivo ha de

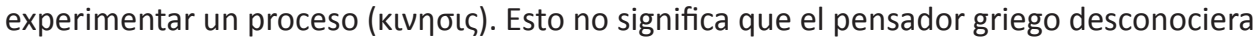
la posibilidad, entendida como uno de los modos de ser, pero sí que estableció y mantuvo con nitidez la diferencia existente entre ambas.

\section{Conclusiones}

El objetivo que persigue Heidegger es mostrar cómo aconteció históricamente que la

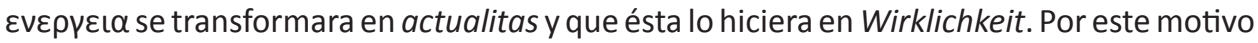

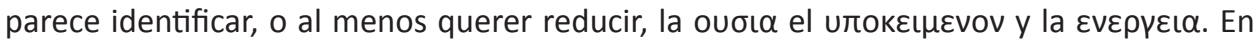
realidad Heidegger no llega a afirmar que Aristóteles entendiera ya con toda rotundidad que la ouoı $\alpha$ es Wirklichkeit; pero sí afirmó que esta última tiene su origen en aquélla que, por tanto, de algún modo la prepararía.

Hay que apuntar que, desde luego, en esta comprensión del ser está latente, pero de un modo que le pertenece esencialmente, la correspondiente comprensión del tiempo. A mi parecer, en la interpretación heideggeriana del tiempo en Kant -y como es sabido, la constitución de la subjetividad kantiana está atravesada por el tiempo-, tiene también un peso decisivo. La razón es que, según las categorías de la modalidad, sus correspondientes esquemas y los postulados del pensamiento empírico, el Dasein, das Wirkliche, lo que existe, es lo presente; es el objeto construido según principios y esquemas que reúne los requisitos materiales necesarios para que el pensamiento pueda determinar que ahora, en presente, existe. Pero desde luego no es así, a mi parecer, como Aristóteles entendió 


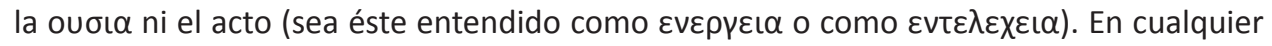
caso, las categorías y el horizonte de comprensión kantiano no puede superponerse sin más sobre la filosofía aristotélica.

Sin embargo, hay algo importante que es preciso reconocer en la interpretación heideggeriana. Ya lo he hecho al recoger la teoría aristotélica contenida en su libro de las Categorías, respecto al carácter de sujeto lógico que le corresponde a la ouoı $\alpha$ por ser antes sujeto ontológico. Desde luego ella lo es y lo es en sentido principal, tanto en el plano ontológico cuanto en el lógico que, como sostiene con nitidez el estagirita, depende de aquél. Es el mismo Aristóteles quien en la Metafísica, por ejemplo, recuerda con insistencia que nosotros "decimos lo que es"; que "lo que es se dice". Es decir, predicamos, decimos algo de algo; y en ese decir, algo opera como sujeto gramatical, apofántico, en definitiva, y algo opera como predicado. Sin duda, éste es un asidero importante al que Heidegger pudo aferrarse para desarrollar la tesis según la cual el sujeto ontológico se transformó en lógico. Ahora cabe entender también la afirmación, quizá algo desconcertante, de nuestro pensador que he recogido antes, según la cual el movimiento, el "llevar a la presencia" es roınoıৎ y ésta puede ser entendida en dos sentidos: como "producir" y como "representar". Todo parece indicar que con "representación" Heidegger se está refiriendo al conocimiento, que él califica, siempre de manera negativa, de representacionista. Pero, para hacer honor a la verdad, hay que decir que Aristóteles jamás habría admitido que la aprehensión de las esencias inteligibles ni su composición y división mediante la afirmación y la negación fuera producción.

De cualquier manera, y dejando esta última consideración atrás, de lo que no cabe duda es que, de no ser por el apoyo que Heidegger creyó encontrar en la teoría aristotélica de las categorías, del juicio y, en concreto, del lóyos aroфavtıkós el objetivo que se había propuesto en el Nietzsche le hubiera resultado más difícil de alcanzar.

Para finalizar, si algo ha de quedar claro es lo que sigue. Por una parte, la diferencia entre el qué-es y el que-es, es bien distinta de la que existe entre posibilidad y actualidad o realidad efectiva. Y no parece justo achacar a Aristóteles esta reducción. Además, no es cierto que esta diferencia sea "obvia", como dice Heidegger, para toda la metafísica. Por otra parte, el estagirita no piensa de ningún modo la $\varepsilon v \varepsilon \rho \gamma \varepsilon\llcorner\alpha$ como realidad efectiva. Por último, no se puede hacer coincidir esta $\varepsilon v \varepsilon \rho ү \varepsilon\llcorner\alpha$, entendida como puro acto, con la existencia, con el que-es de algo. También porque que algo sea no significa que sea pura actualidad. En definitiva, parece que en el Nietzsche asistimos a un ejercicio de superposición de categorías y horizontes, que no habitualmente no es del gusto de Heidegger, aunque fuera el mismo Heidegger quien lo llevara a efecto. Pero no sólo en este central texto, sino $-\mathrm{y}$ esto es lo que ofrece un mayor fundamento para la crítica- en 
el conjunto de su crítica a la metafísica occidental. Porque lo cierto es que, como el mismo

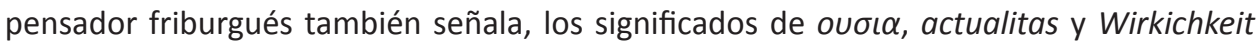
no son intercambiables. De este modo, resulta dudosa la coherencia fenomenológicohermenéutica de la investigación histórica llevada a cabo mediante brillantes pinceladas en el capítulo del Nietzsche consagrado a la Historia del ser.

\section{Bibliografía}

ARISTÓTELES, Categoriae, 1956 [1974], Oxford Classical Text, Oxford, Minio-Paluello (trad. esp.: Categorías, Gredos, Madrid, 1982, introd., trad., notas, Miguel Candel Sanmartín). ARISTÓTELES, Metaphysica, 1957 [1973], Oxford Classical Text, Oxford, W. Jaeger (trad. esp.: Metafísica, Gredos, Madrid, 1994, introd., trad., notas, Tomás Calvo Martínez). ARISTóteles, Physica, 1950 [1973], Oxford Classical Text, Oxford, Ross, W.D. (trad. esp.: Física, Gredos, Madrid, 1995, introd., trad., notas, Guillermo R. De Echandía).

HEIDEGGER, M., 1961: Nietzsche, Günter Neske Verlag, Pfullingen y Vittorio Klostermann, Frankfurt am Main, GA 6.2 (trad. esp.: Nietzsche, Destino, Barcelona, 2001, trad. J.L. Vermal).

HEIDEGGER, M., 1976, Wegmarken («Von Wesen und Begrift der Ф国бıc. Aristóteles. Physik B, 1»), Vittorio Klostermann, Frankfurt am Main, GA 9 (trad. esp.: Hitos,Madrid, Alianza, 2007).

HEIDEgGeR, M., 1975, Die Grundprobleme der Phänomenologie, Vittorio Klostermann, Frankfurt am Main, GA 24.

HEIDEGGER, M., 1992, Platon: Sophistes, Vittorio Klostermann, Frankfurt am Main, GA 19. HEIDEGgER, M., 1983, Einführung in die Metaphysik, Vittorio Klostermann, Frankfurt am Main GA 40 (tra. Esp.: Introducción a la metafísica, Buenos Aires, Nova, 1959). 